\title{
The Central American Master's Program in Astronomy and Astrophysics
}

\author{
Maria C. Pineda de Carias \\ Central American Astronomical Observatory of Suyapa, National \\ Autonomous University of Honduras, Tegucigalpa MDC, Honduras. \\ e-mail: mcarias@hondutel.hn http://www.astro.unah.hondunet.net
}

\begin{abstract}
.
The Master's Program in Astronomy and Astrophysics for Central America arises as part of the project of the National Autonomous University of Honduras to contribute to the establishment of "Astronomy and Astrophysics" as an academic field within the region (Pineda de Carias 1993). In 1997, the same year that the Central American Suyapa Astronomical Observatory (CASAO) was officially inaugurated (within the frame of the VII UN/ESA Workshop on Basic Space Science), a degree course in astronomy and astrophysics at graduate level was approved. In 1998 the program was formally opened for Central American graduate students in physics, mathematics or engineering. In the year 2000, the first group of students is expected to finish their courses. In this document we present the main features of the Master's Program: the syllabus, resources, organization. A discussion of the results achieved and of future tendencies is also included, together with some recommendations about how the international community may contribute to the enhancement of this type of effort, and on how this model may be useful for developing countries.
\end{abstract}

\section{Introduction}

The Master's Program in Astronomy and Astrophysics for Central America arises as part of the project of the National Autonomous University of Honduras to contribute to the establishment of "Astronomy and Astrophysics" as an academic field within the region. In 1997, the same year that the Central American Suyapa Astronomical Observatory (CASAO) was officially inaugurated (within the frame of the VII UN/ESA Workshop on Basic Space Sciences, see Pineda de Carias 1997), a degree course in astronomy and astrophysics at graduate level was approved. In 1998, the program formally opened for Central American graduate students with a background in either physics, mathematics or engineering. Now, at the change of the millenium, the first group of students is expected to finish their courses, research projects and to obtain their degrees.

In this paper, a brief description is presented of what we have achieved during these past three years of intensive work. Seven components are briefly 
described: (i) students, (ii) staff, (iii) curriculum, (iv) research, (v) academic organization, (vi) cooperation and (vii) budgets.

A discussion of the results and future tendencies is included, together with some recommendations on how the international community may contribute to the enhancement of this type of effort and on how this model may be useful for the benefit of developing countries.

\section{Description}

\subsection{Students}

Registration. In August 1997, the Central American Astronomical Observatory of Suyapa announced for the first time its Master's Program in Astronomy and Astrophysics. At that time, 24 students from all the Central American countries, proposed by their national universities, showed interest, but at the time of registration for the propaedeutic course only ten of them formally applied. In 1998, the first group of graduate students (MAA-98) was formally accepted, four out of ten registered for the propaedeutic (see Table 1 - data for this and all tables come from Documents and Archives 2000).

Table 1. Registration

\begin{tabular}{|c|c|c|c|c|c|}
\hline Country & & MAA-98 & & & MAA-99 \\
\hline & & 1997 & 1998 & & 1999 \\
\hline & $\begin{array}{l}\text { Showed } \\
\text { Interest }\end{array}$ & $\begin{array}{l}\text { Propaedeutic } \\
\text { Courses }\end{array}$ & $\overline{\mathrm{MA}} \overline{\mathrm{A}} \mathbf{8}$ & $\begin{array}{l}\text { Showed } \\
\text { Interest }\end{array}$ & MAA-99 \\
\hline Honduras & 6 & 5 & 3 & 8 & 4 \\
\hline Guatemala & 6 & 4 & 0 & 0 & 0 \\
\hline El Salvador & 4 & 0 & 0 & 0 & 0 \\
\hline Nicaragua & 2 & 1 & 1 & 0 & 0 \\
\hline Costa Rica & 3 & 0 & 0 & 0 & 0 \\
\hline Panama & 3 & 0 & 0 & 0 & 0 \\
\hline Total & 24 & 10 & 4 & 8 & 4 \\
\hline
\end{tabular}

The reason for this decrease 24:10:4 was very likely due to, first, their background. Astronomy and astrophysics are not for everybody and a non-solid background in mathematics or physics forced some of them to quit. Secondly, there are economic reasons. In Central America, a great number of students do not have enough money to pay for graduate studies and their families do not accept the idea of having a student member not earning money for a living.

In 1999, with the financial support of the Organization of American States (OAS - see Proyecto OEA-040/98, 1999), the CASAO invited a second group of students for the Master Program (MAA-99). This time, for the selection process, instead of a propaedeutic course we followed a different approach. A letter of intention, a paper on a topic in physics or astronomy and an interview were required. At the end, only four out of eight students remained. 
Progress. The Master's Program covers 20 courses plus a research project. The MAA-98 Group took six courses in 1998, another six in 1999 and this year (2000) they took the eight remaining courses. All of them are now working on their research projects (RP). The MAA-99 Group took seven courses last year (1999) and are taking nine courses in 2000; in 2001 they will take the last four courses and begin their research projects. In our grading scale, the students need to obtain at least $80 \%$ to be approved in a course.

Out of the total of four students who began in 1998 in Group MAA-98, only one abandoned the program. The same happened with the 1999 Group. In 1998, the one who failed in 1998 came from the Physics Department; the one who failed in 1999 came from the Mathematics Department. It seems that only those students related directly to the astronomical observatory are better prepared to succeed.

Table 2. Progress

\begin{tabular}{ccccc}
\hline Group & $\begin{array}{c}\text { 20 Courses } \\
1998\end{array}$ & $\begin{array}{c}\text { Research } \\
1999\end{array}$ & $\begin{array}{c}\text { Project (RP) } \\
2000\end{array}$ & 20001 \\
\hline MAA-98 & 6 & 6 & $8+\mathrm{RP}$ & \\
MAA-99 & 0 & 7 & 9 & $4+\mathrm{RP}$ \\
MAA-01 & & & & 6 \\
\hline Total & 6 & 13 & 17 & 10 \\
\hline
\end{tabular}

Students spend most of the day at the Astronomical Observatory. They may also attend on weekends. Some of them live at the Observatory. On a regular day, we have graduate courses in the afternoon but during the morning our graduate students help with several sections of an undergraduate course Introduction to Astronomy for students from all departments of the university and a course on astronomy via the Internet. At the Astronomical Observatory, graduate students also have to conduct visits from elementary-school groups on Tuesdays, from secondary-school groups on Thursdays and from the general public on Fridays through an activity called "Astronomical Fridays". They prepare an Astronomical Ephemeris each month and collaborate at the library and at the computer center.

Financial Support. As financial support for the graduate students, at CASAO we have offered six positions as Teaching Assistants: three for the Group MAA98 and another three for Group MAA-99. Last year we had five scholarships from the Organization of American States (OAS). See Table 3.

\subsection{Staff}

Only the Chair of the CASAO has a permanent position as Professor. The staff of the Master's Program is made up of visiting professors coming (mostly) from Argentina but also from Brazil, Spain, France and Costa Rica. The total numbers are given in Table 4. In 1998 two came from Brazil and one each from Honduras, Spain, France and Bolivia. In 1999, all five who taught the 1998 Group came from Argentina, while three from that country and one each from Honduras, Spain and Brazil taught the 1999 Group. In 2000, there were again 
Table 3. Financial support

\begin{tabular}{c|ccc|ccc|ccc}
\hline Group & \multicolumn{3}{|c|}{1998} & \multicolumn{3}{c|}{1999} & \multicolumn{3}{c}{2000} \\
\hline & SAO & ODU & OAS & SAO & ODU & OAS & SAO & ODU & OAS \\
\hline MAA-98 & $3 / 4$ & $1 / 4$ & $0 / 4$ & $3 / 3$ & $0 / 3$ & $3 / 3$ & $3 / 3$ & $0 / 3$ & $0 / 3$ \\
MAA-99 & & & & $3 / 4$ & $1 / 4$ & $2 / 4$ & $3 / 3$ & $0 / 3$ & $0 / 3$ \\
\hline Total & $3 / 4$ & $1 / 4$ & $0 / 4$ & $6 / 7$ & $1 / 7$ & $5 / 7$ & $6 / 6$ & $0 / 6$ & $0 / 6$ \\
\hline
\end{tabular}

Notes: SAO $=$ CASAO, ODU $=$ Other Departments of the National

Autonomous University of Honduras, OAS = Organization of American States. Figures give numbers of awards in each category/total numbers of students for each Group in the years 1998, 1999 and 2000, respectively.

five from Argentina and one from Costa Rica, who taught the 1998 Group and one each from Honduras, Brazil, Spain and Costa Rica taught the 1999 Group.

Table 4. Staff

\begin{tabular}{cccccc}
\hline Group & Course & \multicolumn{5}{c}{ Staff } & \\
\hline & & 1998 & 1999 & 2000 & Total \\
\hline MAA-98 & $18 / 20$ & 6 & 5 & 6 & 17 \\
MAA-99 & $14 / 20$ & 0 & 6 & 7 & 13 \\
Total & $32 / 40$ & 6 & 11 & 13 & 30 \\
\hline
\end{tabular}

Visiting professors come to Tegucigalpa for short visits from two up to twelve weeks. Each one is chosen on the basis of his or her field of interest, experience with graduate-school students and research projects. Almost all of them have enjoyed the experience and are willing to collaborate further.

Even though we have no permanent staff, we have the benefit of having experts on the topics we require; and since we have e-mail and Internet connections, students can keep in touch with the visiting professors as needed.

\subsection{Curriculum}

The mission of the National Autonomous University of Honduras is to organize and to develop higher education in order to contribute to the knowledge of reality, the strengthening of national identity, promotion of science and technology, consolidation of ethical values and the development of a culture of quality. This is accomplished through the training of capable and sensitive professionals concerned with the transformation of society.

At CASAO we have the responsibilities of studying and contributing towards the development of astronomy and astrophysics, basic space science and technologies including remote sensing and archaeoastronomy, through academic activities in teaching, research and outreach.

The objectives of the Master's Program in Astronomy and Astrophysics of the CASAO are:

1. To develop, through international cooperation, a regional master's program for the establishment of astronomy and astrophysics as academic fields at the Central American universities. 
2. To contribute to the training of qualified personnel responsible for introducing Central America to the fields of scientific research and knowledge, use and application of astrophysical instrumentation and of space technology.

3. To contribute to the creation of a basic infrastructure and to maintain functioning a Central American Astronomical Observatory where academic and research activities can be carried out.

In order to define the curricular profile, we first identified the regional needs in Central America. There are not enough local professional astronomers in Central America for us to be able to develop astronomy and astrophysics as academic fields. The few astronomers who live in Central America do not have the impact they wish to have on education, communications and on the enterprises in which knowledge and technology of basic space science could be of great application.

Graduate students who finish their master's program will be able to work at universities, astronomical centers, public and private institutions and enterprises with projects on science and technology or to continue higher education toward a doctorate.

Students graduating from this Master's Program will have acquired a broad knowledge of astronomy and astrophysics through 20 courses and a research project, covering seven fields. Fundamental Astronomy in courses Nos. 1 and 2, Physics in courses Nos. 3-7, Astronomy and Astrophysics in courses Nos. 8-13, Instrumentation and Astrophysical Techniques in courses Nos. 14-17, History of Astronomy in course No. 18, Education in Astronomy in course No. 19. and research through all the above mentioned courses plus the seminar and a research project leading to a thesis (see Table 5).

Astronomers graduating from this Master's Program will be able to teach at a higher level; to handle and to understand the functioning of several instruments, processing and analysis of data techniques, computer systems and international data bases; to design and to develop original and modern projects of research; and to use the abilities and techniques learned in other fields of research and applied technologies.

Astronomers graduating from this Program will have an attitude of continual training in new theories and techniques as they are developed; they will frequently examine current publications and make contact with active researchers; they will maintain a competitive level of training in order to develop satisfactorily their professional career.

For the Master's Program there have been approved academic rules in which methodology and procedures for evaluation of staff and students are included. As part of the syllabus, a synthetic program for each course is included, however these programs could be enriched for the benefit of the students for each professor at the time they have to teach each course.

As strategies for developing the Master Program we never have more than two courses at the same time; because classes for each course last from two to twelve weeks, methodology is intensive; however evaluation is over extended periods covering up to half a year and pass grade is $80 \%$. Historical records for each student are kept and maintained updated. 
Table 5. Curriculum

\begin{tabular}{cc}
\hline No. & Subject Matter \\
\hline 1 & Introduction to Astronomy and Astrophysics \\
2 & Celestial Mechanics and Classical Astronomy \\
3 & Spectroscopy \\
4 & Nuclear and Particle Physics \\
5 & Radiative Processes and Radiation Transfer \\
6 & Physics of Fluids \\
7 & Physics of Plasma \\
& \\
8 & Solar System \\
9 & Solar Physics \\
10 & Stellar Structure and Evolution \\
11 & Galactic Physics and Stellar Systems \\
12 & Physics of Interstellar Medium \\
13 & Extragalactic Physics and Cosmology \\
& \\
14 & Astrophysical Instrumentation \\
15 & Data Processing Techniques \\
16 & High Resolution Techniques \\
17 & Remote Sensing \\
& \\
18 & Archaeoastronomy \\
19 & Didactics of Astronomy and Astrophysics \\
20 & \\
21 & Seminar- open \\
\hline
\end{tabular}

For logistic support of the Master's Program, at CASAO, we have a library with several hundreds of journals and books on Astronomy and Astrophysics; a computer center equipped with astronomical software (i.e.: IRAF operating over LINUX) and Internet links and access to e-mail; a conference room equipped with slides and overhead projectors; a permanent exhibition of more than 100 pictures of the universe; offices for staff and students; and observational facilities such as a 42-cm telescope equipped with a CCD camera and Johnson filters, a photometer and other accessories.

\subsection{Research}

Research is a rather slow process that needs, on the one hand, well trained researchers and students with a solid background, who are clear about what they want to do and what they are looking for; and, on the other hand, good facilities and optimum conditions to pursue their goals, i.e. computers, software, journals, books, Internet, and so forth. 
In Honduras, a few years ago, conditions in astronomy and astrophysics were very poor. Even though one may have been a well-trained researcher, one had nobody to talk to or work with. Now, at CASAO, with the Master's Program in Astronomy and Astrophysics, after having taught several courses on astronomy and astrophysics, after having interacted with several research institutions via almost two dozens of active researchers, things have changed and research has begun to grow.

At CASAO we have been working on Education Projects: "An Astronomical Observatory for Central America" is the main project, "The Master's Program in Astronomy and Astrophysics" is one of its components. "Teaching of Astronomy" at different levels: elementary, secondary and university is another project in which schoolteachers also participate (Pineda de Carias 1993).

Also, because of the size of the telescope $(\sim 0.4-\mathrm{m})$ we have been involved in "Near-Earth Objects" projects. We were lucky to have a meteorite falling in Honduras. We were thus able to organize research groups with international collaboration. A paper was published in Meteoroids last year.

Now, with NASA and the Central American Commission of Environment, we are collaborating in a project that uses satellite observations for understanding environmental change in Central America. This is part of a broader project for monitoring the whole Earth.

With the collaboration of Visiting Professors from Argentina and Brazil, graduate students have begun to work on: "Kinematics of stars toward Collinder 121 open cluster", "Dynamical Structures in the outer region of Saturn" and "The effect of new degrees of freedom in the Cosmological Model". It is important to emphasize that the students chose these topics and fields of work themselves, with the collaboration of our staff. This is a new stage of development for our astronomical center.

\subsection{Academic Organization}

The Master's Program is part of CASAO, which is an academic unit of the National Autonomous University of Honduras. At the Astronomical Observatory we have the Secretary, Administration, Services, Computer Center, the Library and the dome, which houses the telescope and the observational equipment. At present, the Director of CASAO is also President of the Central American Assembly of Astronomers (CAAA) which, each year, organizes a CURso Centraoamericano de Astronomía y Astrofísica (CURCAA) -a course conducted in Spanish for the whole region. (See Figure 1.)

There are three academic divisions at the Central American Astronomical Observatory.

Astronomy and Astrophysics which includes the Master's Program, a general course of Introduction to Astronomy for all students, Astronomy via Internet, Education Projects and visits to the Observatory and the Astronomical Ephemeris.

Archaeoastronomy, in which we develop seminars and a project on Mayan Archaeoastronomy, taking advantage of the Mayan site of Copán. 


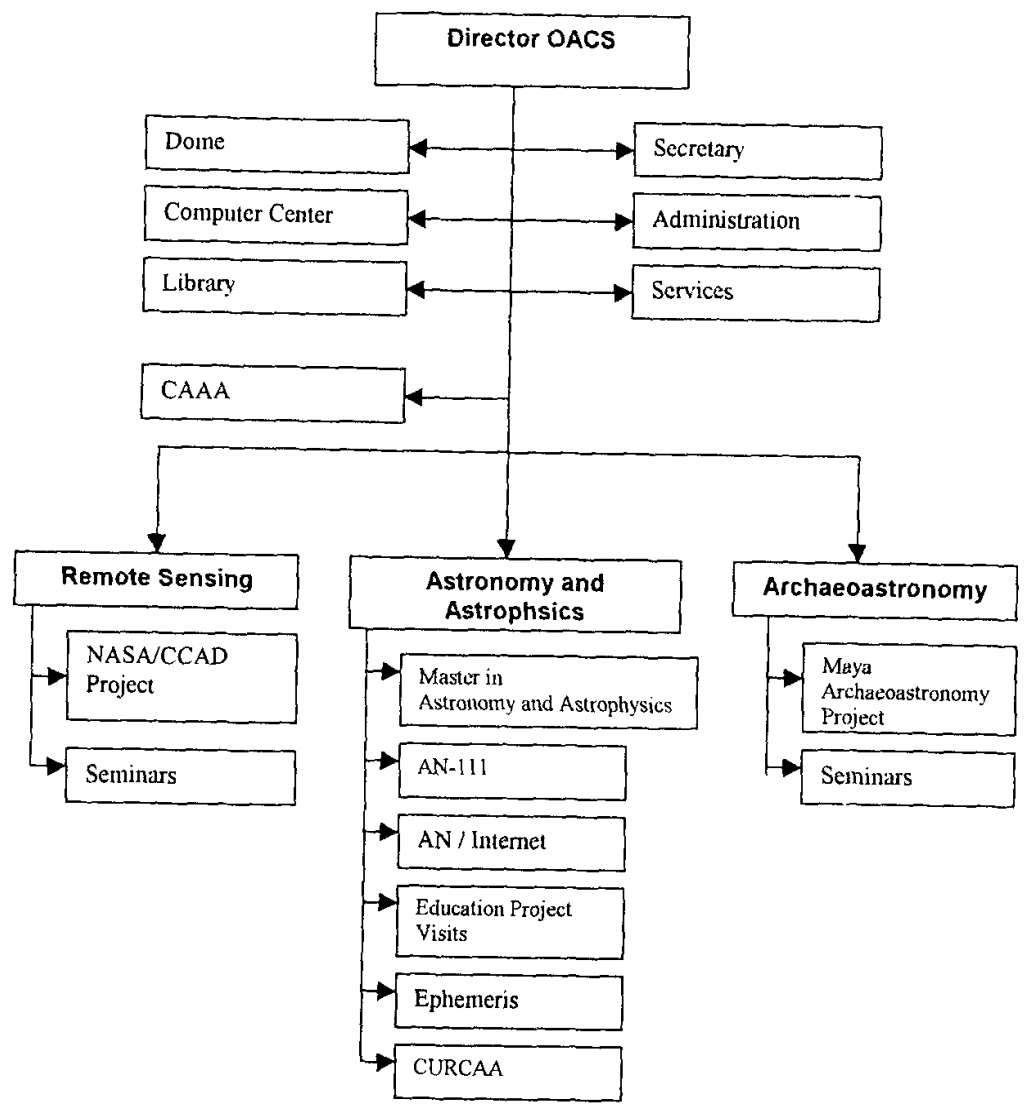

Figure 1. Central American Observatory of Suyapa: Organigram

Remote Sensing, in which we develop some seminars on remote sensing and digital image processing, and in which we also have the NASA/CCAD Project.

At the National Autonomous University of Honduras, graduate studies are responsible to a Graduate Studies Direction which in turn is responsible to the President of the University. An Academic Committee, integrated by two staff and two student members, is also functioning. See Figure 2.

Because every month we receive a visiting professor, we can say that on average we have a proportion of 2:5 staff versus administrative members. However, these five administrative members are the Secretary, Administrator, Janitor and two Instructors, so we feel we need to raise the number of technicians.

The proportion of staff to students on average is $2: 6$, which is too low. Therefore, we need to raise the number of permanent professors, because for the year 2001 the number of students will increase.

The environment at the Astronomical Observatory is pleasant and everybody feels comfortable doing his or her own work. 


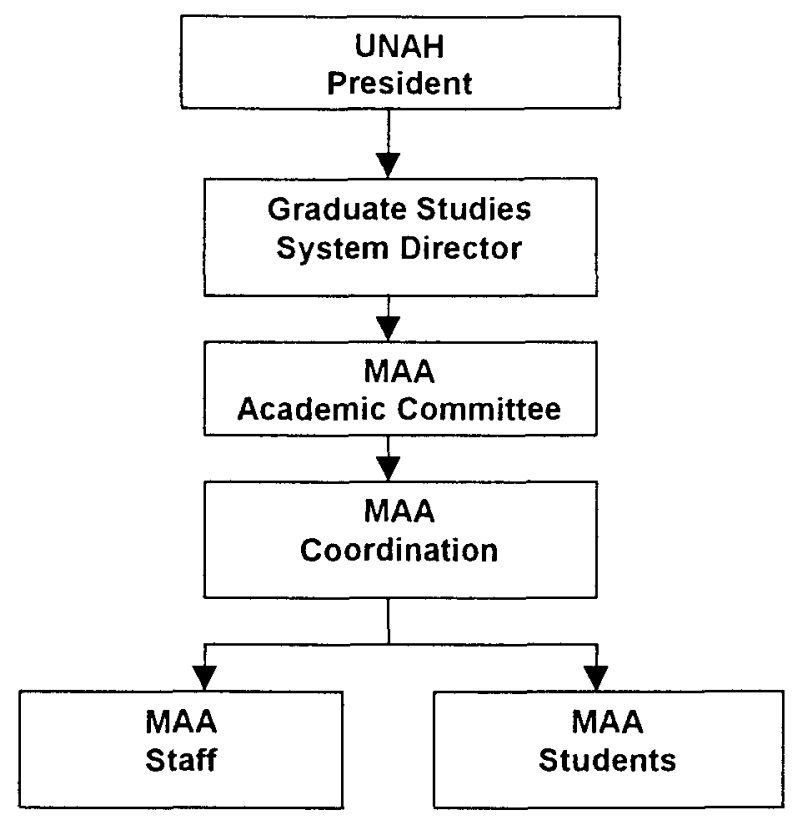

Figure 2. Astronomy and Astrophysics Master's Program: Organigram

\subsection{Collaboration}

For the development of the Master's Program, the main collaboration has come from Visiting Professors who teach the courses. They have come mainly from the Observatory of Córdoba (Argentina), Observatory of La Plata (Argentina), Space Physics and Astronomy Institute (Argentina), Theoretical Physics Institute of São Paulo University (Brazil), Department of Astrophysics of Madrid Complutense University (Spain), Canary Island Astrophysics Institute (Spain) and Astrophysics Laboratory of Costa Rica University.

External financial support has come mainly from the Organization of American States (OAS - see Proyecto OEA-040/98, 1999). They first funded the Project "Inter-Institutional and Academic Strengthening of CASAO". For next year we have presented the project "Strengthening and Integration of the Centers for the Development of Astronomy and Astrophysics in Central American Countries" which is an international project jointly presented by Honduras, Costa Rica and Nicaragua. Next year, Costa Rica will host the VI Central American Course in Astronomy and Astrophysics (VI-CURCAA). Nicaragua, after having the first astronomer graduated from the Master's Program of Honduras, will be working toward developing astronomy as an academic activity. In Honduras, the Central American Astronomical Observatory will continue its activities and projects.

In Central America, we want to work together within the region. The underlying philosophy of CASAO is that each country should have a core of astronomers, with their own facilities in their own country, all working as one regional observatory. 
At CASAO, we have also received collaboration from the Teaching of Astronomy Development Commission of the International Astronomical Union (TAD/IAU) and from the United Nations and European Space Agency (UN/ESA) Workshops on Basic Space Science Group.

\subsection{Budget}

More than $50 \%$ of the budget of CASAO comes from the National Autonomous University of Honduras. This covers salaries for staff and administrative personnel, educational material, travel and equipment.

About $40 \%$ has come from the Organization of American States (OAS) to fund: scholarships for students, trips for Visiting Professors, books and equipment for the Central American Astronomical Observatory.

Two other sources have provided $2 \%$ of the budget for the Astronomical Observatory. The European Space Agency and the United Nations donated some computers. From the TAD/IAU we have received funds for regional observational campaigns, some equipment and funds for repairs, after Hurricane Mitch damages.

\section{Some Results}

Astronomy and astrophysics are academic fields now established at the National Autonomous University of Honduras for the benefit of Honduras, Central America, and the international community.

As a graduate program, the Master in Astronomy and Astrophysics is a model of a well organized academic unit, with international recognition and support from prestigious international universities and organizations.

The success of the Master in Astronomy and Astrophysics program has depended on the local capacity to manage it (staff and students) and on the opportune assistance from the international community. This program is now a real professional alternative for the youth of the area and a good model to be followed by developing countries.

\section{Recomendations}

The international community of astronomers may help:

by creating links between developed and developing countries;

by providing visiting professors willing to come to developing countries to collaborate as they may be needed;

with funds for scholarships for graduate students to finish their degrees up to the highest level, while guaranteeing and stimulating them to remain in their own countries.

Acknowledgments. I want to thank the International Astronomical Union and the Local Organizing Committee of the 24th General Assembly for allowing me, the first Central American Astronomer to attend a IAU-General Assembly, 
to present and discuss a paper. I know that after this benchmark or "candle", colleagues and students of mine will follow the path, and in future meetings you will be hearing more about the Central American astronomers and their work.

\section{References}

Documents and Archives 2000, Dcouments and Archives at the Central American Observatory of Suyapa. National Autonomous University of Honduras.

Pineda de Carias, M.C. 1993, Proyecto Un Observatorio Astronómico para Centroamerica. UNAH. Madrid. España.

Pineda de Carias 1997 in Report on the 7th UN/ESA Workshop on Basic Space Science: Small Astronomical Telescopes and Satellites in Education and Research., Tegucigalpa.

Proyecto OEA-040/98 1999, Fortalecimiento Interinstitucional y Academico del Observatorio Astronómico de Suyapa Organization of American States.

\section{Discussion}

Fierro offered congratulations on the fine work done in Central America but thought more effort should be put into sending students to developed countries to work on their doctorates. She pointed out that it has been found difficult to persuade visiting astronmers to spend long enough in Honduras to give doctorallevel courses. She also recommended that students should be taught English. Pineda de Carias emphasized that the Master's Program was intended to prepare students for several different career paths. One possibility is indeed for successful students to go on to doctoral studies and the universities from which visiting staff have come are willing to help. She admitted that the Program had experienced some diffciulties, as all new projects do at first, but she believed that these problems were being successfully dealt with. There is an English-language requirement for admission to the Program and many students voluntarily take courses beyond this requirement. Rosenzweig suggested that the Central Americans should contact Venezuelan astronomers, who have degree programs at the mater's and doctoral levels. (Editor's Note: see the paper by Rosenzweig, pp. 205-209.) 